\title{
Photochemical Polymerization of Methyl Methacrylate in Benzophenone-2-Propanol System
}

\author{
Katsuhiko Hirano, Harunobu Sekino, Mitsuyoshi Kurita, Yuusaku Asami, \\ and Ryoichiro TAKAGI \\ Shibaura Institute of Technology, Department of Industrial Chemistry, \\ 3-9-14 Shibaura Minato-ku, Tokyo, 108, Japan.
}

(Received May 10, 1978)

KEY WORDS Benzophenone / 2-Propanol / Methyl Methacrylate / Photochemical Polymerization / Ketyl Radical /

The photoreduction of benzophenone to benzopinacol in 2-propanol is a well known photochemical reaction. A ketyl radical is formed as an intermediate in this reaction. In the presence of a vinyl monomer such as methyl methacrylate in the solution, polymerization is expected to be induced by the ketyl radical.

Heine, et al., reviewed this type of polymerization, and reported that the polymerization is very slow when benzophenone and alkyl acrylates are exposed to light in 2-propanol. ${ }^{1}$ There is, however, no detailed study for this type of reaction.

In this study, we have examined the possibility of the polymerization of methyl methacrylate (MMA) by the ketyl radical produced by an $\mathrm{H}$ atom abstraction of an excited benzophenone from 2-propanol.

All chemicals used were reagent grade (Wako Pure Chemical Ind. Ltd.). The monomer was washed with sulfuric acid, anhydrous sodium sulfite and water, then dried over calcium hydride, and distilled under nitrogen at reduced pressure. 2-Propanol was dried over barium oxide before the distillation. Dimethylsulfoxide (DMSO) was dried over calcium hydride and distilled under nitrogen at reduced pressure. Benzophenone was recrystallized three times from ethanol. The light source was $500 \mathrm{~W}$ mercury lamp (Usio $\mathrm{HB} / \mathrm{B}$ ), and the UV light waves, of a length shorter than $300 \mathrm{~nm}$, were cut by using Pylexglass lenses. The sample solution was irradiated in a drum-type cell $2 \mathrm{~cm}$ in diameter and $3 \mathrm{~cm}$ in length. The sample solution was about $8 \mathrm{ml}$. Before the irradiation, the sample solution was deaerated by bubbling nitrogen gas through it for half an hour. The cell was cooled by circulating water from the thermostat kept at $30^{\circ} \mathrm{C}$. After irradiation, the sample solution was poured into $40 \mathrm{~m} l$ of methanol. The polymer precipitated by the methanol was filtered and dissolved in acetone. The polymer was reprecipitated from acetone by water, dried at $30^{\circ} \mathrm{C}$ for $24 \mathrm{~h}$ and weighed. The molecular weight of polymer was determined from the viscosity in benzene, using the equation $[\eta]=K M^{\alpha}$, with the values of $K$ and $\alpha$, $5.5 \times 10^{-5}$, and 0.76 , respectively. ${ }^{2}$ Benzopinacol was precipitated by adding a large amount of 2-propanol to the irradiated solution, since its solubility in 2-propanol is low.

Figure 1 shows that the poly(methyl methacrylate) formation increases linearly with increasing irradiation time in the equivolume solution of 2-propanol and MMA containing various concentrations of benzophenone. All irradiations were performed with intense absorption close to the front window of the $3-\mathrm{cm}$ cell, because $\mathrm{Hg}$ arc irradiation above $300 \mathrm{~nm}$ implies that the $366 \mathrm{~nm}$ band is most important, and at $366 \mathrm{~nm}$, the extinction coefficient of benzophenone is about $100 \mathrm{M}^{-1} \mathrm{~cm}^{-1}$. The slope of the lines in Figure 1 gives the polymerization rates. The rate is expressed by the concentration of the monomer converted to the polymer per second.

Figure 2 shows that the polymerization rate is 


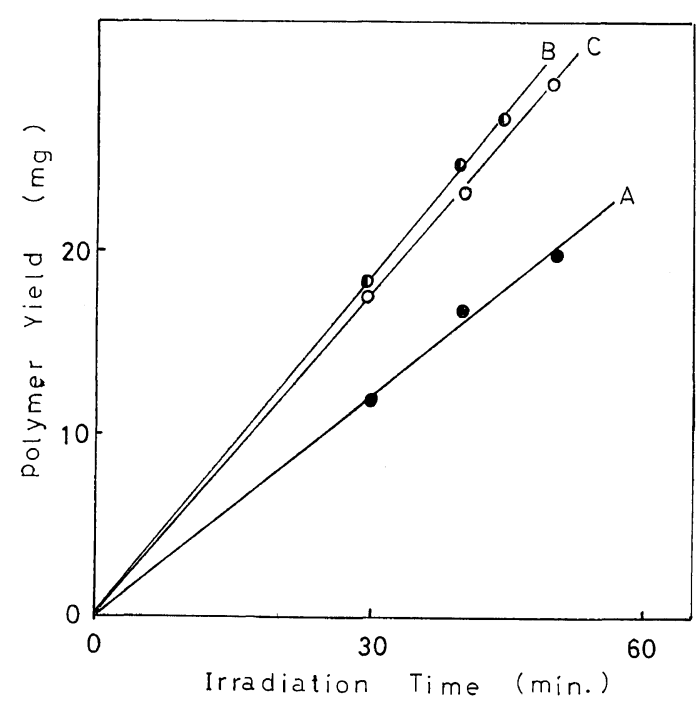

Figure 1. Effect of irradiation time on the polymer yield in 2-propanol solutions with 0.005-M (A), 0.03-M (B), and 0.1-M (C) benzophenone.

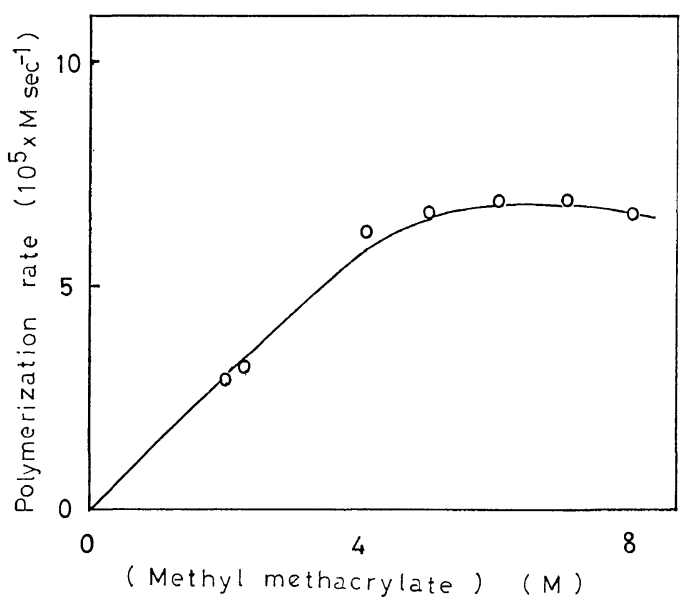

Figure 2. The dependence of the polymerization rate on the monomer concentration in a 2-propanol solution with 0.1-M benzophenone.

proportional to the monomer concentration in the low range. At high MMA concentrations, monomer quenching must occur, since olefins are known to quench excited aromatic ketones. ${ }^{3}$

The molecular weight of polymers were found to be about 10000 , and this value was independent of either the benzophenone or the monomer concentration. Since the monomer concentration

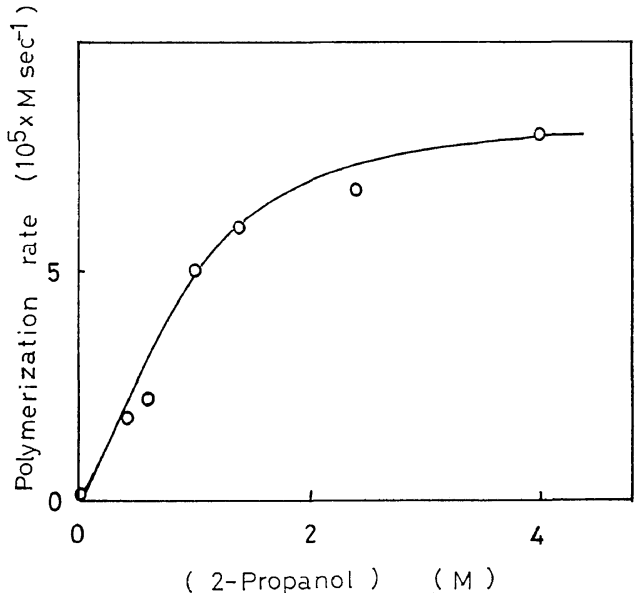

Figure 3. The dependence of the polymerization rate on 2-propanol in the DMSO solution with 0.1-M benzophenone and 4.76-M MMA.

did not affect the degree of polymerization, no chain transfer to the solvent occurred.

Table I shows that the pinacol formation was reduced by adding a small amount of MMA in 2-propanol containing 1-M benzophenone.

Table I. The effect of MMA on the photochemical yield of benzopinacol in 2-propanol with 1-M benzophenone

\begin{tabular}{cc}
\hline Concn of MMA, M & Relatie yield of Pinacol \\
\hline 0 & 1 \\
0.01 & 0.65 \\
0.02 & 0.15 \\
0.04 & 0 \\
\hline
\end{tabular}

Figure 3 indicates the effect of 2-propanol on the polymerization rate in the benzophenoneMMA solution when DMSO is used as a solvent. From the fact that no polymer was formed in the absence of 2-propanol, it is evident that the benzophenone does not sensitize the polymerization directly. The slowing down of the rate increase at high concentrations of 2-propanol may be due to a decrease in polymer solubility as the fraction of 2-propanol increases in the solution.

These results have lead to the conclusion that the ketyl radical, produced by the $\mathrm{H}$-atom abstrac- 
Photochemical Polymerization of Methyl Methacrylate in Benzophenone-2-Propanol System

tion of the excited benzophenone from 2-propanol, initiates the polymerization of MMA.

\section{REFERENCES}

1. H. G. Heine, H. J. Rosenkranz, and H. Rudolph,
Angew. Chem. Int. Ed., 11, 970 (1972).

2. Nihon Kagakukai, "Kagaku Binran," The Chemical Society of Japan, Ed., Maruzen Co., Tokyo, 1975, p 592.

3. P. J. Wagner and G. S. Hammond, J. Am. Chem. Soc., 88, 1245 (1966). 